\title{
Correction: Identification of Informed Consent in Patient Videos on Social Media: Prospective Study
}

Jane O'Sullivan ${ }^{1}$, MBBS; Cathleen McCarrick ${ }^{2}$, MBBS, MPhil; Paul Tierney ${ }^{3}$, MBBS, PhD; Donal B O'Connor ${ }^{4}$, MBBS, MD; Jack Collins ${ }^{1}$, MBBS; Robert Franklin ${ }^{1}$, MBBS

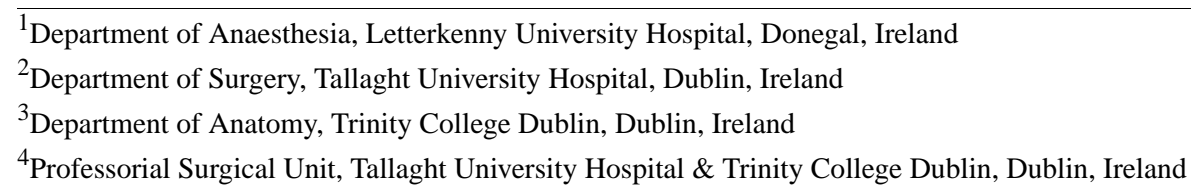

\section{Corresponding Author:}

Cathleen McCarrick, MBBS, MPhil

Department of Surgery

Tallaght University Hospital

Tallaght

Dublin, D24 NR04

Ireland

Phone: 35314142000

Email: cathleen.mccarrick@gmail.com

\section{Related Article:}

Correction of: https://mededu.jmir.org/2020/2/e14081/

(JMIR Med Educ 2020;6(2):e25045) doi: 10.2196/25045

In "Identification of Informed Consent in Patient Videos on Social Media: Prospective Study" (JMIR Med Educ 2020;6(2):e14081) the authors noted one error.

The corresponding author affiliation was inadvertently published with the incorrect phone number. The correct phone number has now been added as follows: 35314142000 .
The correction will appear in the online version of the paper on the JMIR Publications website on October 30, 2020, together with the publication of this correction notice. Because this was made after submission to PubMed, PubMed Central, and other full-text repositories, the corrected article has also been resubmitted to those repositories.

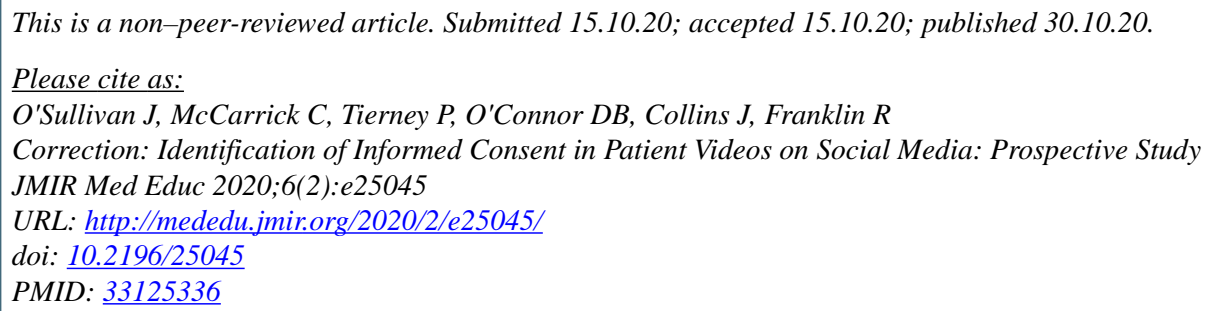

CJane O'Sullivan, Cathleen McCarrick, Paul Tierney, Donal B O'Connor, Jack Collins, Robert Franklin. Originally published in JMIR Medical Education (http://mededu.jmir.org), 30.10.2020. This is an open-access article distributed under the terms of the Creative Commons Attribution License (https://creativecommons.org/licenses/by/4.0/), which permits unrestricted use, distribution, and reproduction in any medium, provided the original work, first published in JMIR Medical Education, is properly cited. The complete bibliographic information, a link to the original publication on http://mededu.jmir.org/, as well as this copyright and license information must be included. 